\title{
DE STRUCTUUR VAN DEN AFZET MET BETREKKING TOT DE VERBIZONDERING DER KOSTEN IN HET SEIZOENBEDRIJF
}

door Dr. H. J. van der Schroefl

Onder de vraagstukken, die de seizoenschommelingen in de productie in het leven roepen, neemt de verbizondering van de kosten der inelastische productiemiddelen een belangrijke plaats in. Door hun ondeelbaarheid kan de capaciteit dezer productiemiddelen niet aan de schommelingen in den omvang van de voortbrenging worden aangepast, met het onvermijdelijk gevolg, dat een overcapaciteit ontstaat, zoodra de omvang van de produc tie kleiner wordt dan die, waarop de productiecapaciteit werd ingesteld. Doordat de zich periodiek voordoende maxima in de bedrijfsbezetting de grootte van het productie-apparaat bepalen, beschikt het seizoenbedrijf buiten deze spitsmomenten over een productiecapaciteit, welke grooter is dan de behoefte van het oogenblik. Een deel van de beschikbare produc tiecapaciteit zal ongebruikt blijven; zelfs komt het voor, dat buiten het seizoen voor het geheele productieapparaat geen aanwendingsmogelijkheid bestaat.

De aanwezigheid van een overcapaciteit doet in het kader van het probleem van den kostprijs de vraag rijzen, of de daaraan verbonden offers: als productiekosten kunnen worden aangemerkt. Voor een seizoensovercapaciteit is deze vraag niet moeilijk te beantwoorden. Bij een rationeele: organisatie van het productieproces zullen seizoenschommelingen in de productie slechts voorkomen in die gevallen, waarin een geregelde opvolging van de productieprocessen in den loop van het jaar niet mogelijk is, doordat grondstoffen worden verwerkt dan wel goederen worden voortgebracht, die voor opslag niet of minder geschikt zijn, of waarin kosten en andere overwegingen (prijsrisico) zich tegen voorraadvorming verzetten. Het vormen van voorraden schept de mogelijkheid van de vergelijkmatiging der productie en daarmede een kostenvoordeel, doordat een overcapaciteit wordt vermeden. Zoo voorraadvorming althans technisch mogelijk is, staat de producent, die in de technische voortbrenging dan wel in den afzet van zijn product den invloed van het seizoen ondervindt, voor de keuze, òf de productie door middel van voorraadvorming te vervlakken òf het nadeel van een overcapaciteit bij seizoenproductie te aanvaarden. Wil de producent - zoo hebben wij ter andere plaatse uiteengezet ${ }^{1}$ ) - de nadeelen van de overcapaciteit vermijden, dan zal hij de nadeelen van de voorraadvorming moeten aanvaarden en omgekeerd, wenscht hij de nadeelen van de voorraadvorming niet te aanvaarden, dan zal hij de nadeelen van de overcapaciteit moeten dragen. De afweging van deze beide nadeelen zal voor zijn keuze beslissend zijn. De overcapaciteit, welke op grond van deze kostenafweging doelbewust wordt aanvaard, is economisch onvermijdbaar, waaruit volgt, dat de offers, aan deze overcapaciteit verbonden, deel uitmaken van de kosten van de voortbrenging en als zoodanig in den kostprijs der voortgebrachte producten behooren te worden opgenomen.

Ten aanzien van de verbizondering der kosten van de overcapaciteit schept het geval van seizoenproductie, d.i. in die gevallen, waarin de

1) Over den invloed van het seizoen op de bedrijfshuishouding en haar bedrijfspolitiek. Openbare les, 1938, biz. 14.

m a b blz. 2 
invloed van het seizoen zich primair op de technische voortbrenging doet gevoelen, geen bizondere moeilijkheden. Deze kosten toch staan in rechtstreeksche oorzakelijke betrekking met de producteenheden, welke in het seizoen worden voortgebracht en elke producteenheid moet derhalve een gelijk aandeel in deze kosten dragen. In het geval van parallelisatie moeten de kosten van de overcapaciteit over de verschillende producten worden verbizonderd in verhouding van het aantal werkeenheden van de productiecapaciteit, dat voor het betreffende product effectief wordt aangewend.

Een probleem wordt de verbizondering van de kosten, verbonden aan de beschikbare inelastische productiecapaciteit (capaciteitskosten) bij de bedrijven, die den seizoeninvloed op de productie door de seizoenfluctuaties van hun afzet ondervinden. De vraag naar vele goederen is niet gelijkmatig, waardoor de afzet van de bedrijven, die deze goederen voortbrengen, tluctuaties vertoont. Wij staan hier ter plaatse bij de oorzaken, die tot seizoenschommelingen in de consumptie leiden, niet stil. Deze wisselingen zijn voor een deel terug te brengen op de natuurlijke verschillen van den omvang der behoeften op de verschillende momenten van de jaar-, maand-, week- of dagperiode, voor een ander deel op den smaak, gewoonte en traditie van den consument. ${ }^{2}$ ) De schommelingen in den afzet, die door de ongelijkmatigheid van de vraag naar goederen en diensten ontstaan, doen vraagstukken rijzen met betrekking tot de verbizondering van de kosten der overcapaciteit. Zooals wij boven vaststelden, zetten deze schommelingen in den afzet in de gevallen, waarin voorraadvorming technisch niet mogelijk ${ }^{3}$ ) dan wel economisch niet rationeel is, zich in de productie voort. Een overcapaciteit van het inelastische deel van het productie-apparaat, waartoe in de eerste plaats de duurzame productiemiddelen moeten worden gerekend, is daarvan het onvermijdelijk gevolg. Het zijn de afnemers, die door de ongelijkmatigheid van hun vraag die overcapaciteit doen ontstaan en bij de verbizondering van de kosten (de kosten van de overcapaciteit daarbij inbegrepen) zal moeten worden gezien, welke afnemers, c.q. groepen van afnemers voor de kosten verantwoordelijk zijn. Voor deze verbizondering zal kennis van de structuur van den afzet noodig zijn, opdat vastgesteld kan worden, welke afnemers de verantwoordelijkheid voor het ontstaan van de seizoenspits dragen. Het is de bedoeling van dit opstel om den invloed van de structuur van den afzet op de verbizondering der kosten te analyseeren, teneinde de grondslagen vast te stellen voor de verbizondering van de kosten der overcapaciteit in bedrijven met een seizoenafzet.

Aan de hierboven bedoelde analyse mogen wij een enkel woord laten voorafgaan omtrent een tweetal in de praktijk veel voorkomende methoden van verbizondering, waarvan er een onmiddellijk als foutief van de hand kan worden gewezen. Met deze laatste doelen wij op die wijze.van verbizondering, waarbij de kosten van de overcapaciteit als kosten worden beschouwd van den afzet in de periode, waarin de overcapaciteit voorkomt. Het zal weinig betoog behoeven, dat deze zienswijze geheel foutief is. Er bestaat geen verband tusschen de kosten van de overcapaciteit en

2) Zie mijn Openbare les, b]z. 8-11.

3) Men denke bijv, aan de dienstverleeningsbedrijven, die voor het meerendeel groote schommelingen in hun bedrijfsbezetting vertoonen.

m a b blz, 3 
den afzet in de slappe maanden. Welke gevallen ook zijn te onderscheiden, in elk geval ligt de kritische oorzaak van het ontstaan van de overcapaciteit bij de seizoendrukte. Het organische verband tusschen den afzet in de verschillende jaarperioden is in de opvatting, volgens welke de kosten van de overcapaciteit ten laste van den afzet van de slappe maanden zouden moeten worden gebracht, geheel overzien. Deze foutieve kostprijsberekening zal leiden tot een averechtsche prijspolitiek, aangezien het bedrijf in den tijd van de kleinste vraag door zijn vermeenden hoogeren kostprijs met een hoogeren vraagprijs ter markt zou komen dan tijdens de momenten van den grootsten afzet, waarop blijkens het seizoen de behoefte van het goed het grootst is. Voor een juiste verbizondering zal de organische samenhang in afzet en productie wel in het oog moeten worden gehouden.

De eenvoudigste wijze, waarop bij de verbizondering van de kosten de organische samenhang van de deelen van den atzet kan worden gezien is die, waarbij het totaal van de kosten van den seizoencyclus in betrekking wordt gebracht met het totale kwantum der in deze periode voortgebrachte en afgezette producteenheden. De gedachte, die aan deze opvatting ten grondslag ligt, is dat voor de voortbrenging van de producteenheden in en buiten het seizoen de aanwezigheid van het ondeelbare productie-apparaat wordt vereischt. De kosten van dit productie-apparaat en ook de kosten van de seizoensovercapaciteit - zoo wordt geredeneerd - hangen derhalve met dit aantal geproduceerde eenheden samen. Alle producteenheden, onverschillig of $z \mathrm{ij}$ in of buiten het seizoen worden voortgebracht, moeten derhalve een gelijk aandeel in de kosten dragen. Technisch is deze verbizondering hoogst eenvoudig. De berekening komt neer op een doorsneecalculatie, waarbij het totaal van de kosten over de producten wordt omgeslagen. Bij deze wijze van verbizondering draagt iedere producteenheid, daar ook een omslag plaats vindt van de kosten der onbezette werkeenheden, een gelijk aandeel in de kosten van de overcapaciteit.

De hier geschetste wijze van verbizondering heeft haar grooten eenvoud voor. En het is deze eenvoud, die de praktijk menigmaal naar deze methode doet grijpen, zonder dat men zich steeds voldoende rekenschap geeft of deze methode principieel als juist aanvaardbaar is en toepasselijk is op het gegeven geval. Nog al te veel ziet men in de praktijk in de kostprijsberekening geen economisch probleem, dat een nauwkeurige analyse vraagt van het oorzakelijk verband tusschen kosten en productie, maar een rekenkundig vraagstuk, hoe uit de kosten voor een hoeveelheid producten de kosten voor een eenheid kan worden berekend. Het is veelal deze simplistische opvatting, welke tot de hier beschreven doorsneecalculatie als rekenkundige oplossing leidt, wijl men het economische probleem, dat achter de calculatie schuilt, niet heeft gezien.

De mindere of meerdere eenvoudigheid van de technische berekening speelt uiteraard voor onze beoordeeling geen rol. Het gaat om de beoordeeling van de juistheid van de grondslagen, waarop de berekening berust. Hoe staat het daarmede bij deze methode? Is de doorsneecalculatie - zoo dienen wij ons af te vragen - theoretisch verdedigbaar? Het antwoord op deze vraag moet luiden, dat in sommige gevallen deze wijze van verbizondering als juist kan worden aanvaard. Het is niet moeilijk om aan te geven, welke gevallen dit zullen zijn. De doorsneecalculatie impliceert een gelijke betrekking tusschen elk van de product-

$\mathrm{m}$ a b $\quad$ blz. 4 
eenheden en de kosten van de overcapaciteit, waaruit volgt dat de bedoelde wijze van verbizondering dan alleen kan worden toegepast, indien de structuur van den afzet zoodanig is, dat kan worden gezegd, dat alle producteenheden in gelijke mate voor het ontstaan van de overcapaciteit aansprakelijk zijn. Alleen in het geval, dat de seizoenschommeling ontstaat door verhoogde vraag van afnemers, die geregeld ook buiten het seizoen afnemen - zoo meerdere productsoorten worden voortgebracht, nog slechts dan, wanneer deze producten een gelijke seizoenschommeling in den afzet hebben ${ }^{4}$ ) - , is de voorwaarde vervuld, die voor het toepassen van deze methode van verbizondering noodzakeliik is. Bij deze structuur van den afzet is een als boven bedoelde samenhang tusschen het totale kwantum product en de kosten van de overcapaciteit aanwezig. 5) Zoodra echter in de afnemers economisch zelfstandige groepen kunnen worden onderscheiden of indien bij parallelisatie de afzet der verschillende producten een verschillende economische karakteristiek bezit, kan de doorsneecalculatie niet worden toegepast. Wat dit laatste betreft, wijzen wij op de gevallen, waarbij meerdere producten worden voortgebracht, waarvan een of meer geen seizoenproduct is, of waarbij de seizoenschommeling in den afzet voor alle producten niet dezelfde is. In deze gevallen zal niet langer een gelijke betrekking tusschen producten en overcapaciteit bestaan. Zelfs als er één product is, kan het zijn, dat als gevolg van de samenstelling van den afzet de kosten van de overcapaciteit niet gelijkelijk kunnen worden omgeslagen. Zoodra er meerdere groepen van afnemers zijn, die in en buiten het seizoen verschillende hoeveelheden afnemen, komt het vraagstuk anders te liggen. Men behoeft daarbij - om het eenvoudigste geval te nemen — slechts te denken aan een groep geregelde afnemers, die gedurende het geheele jaar het product betrekt, en een groep van afnemers, die uitsluitend in het seizoen afneemt. Aan de voorwaarde, die wij voor de toepassing van de doorsneecalculatie hebben gesteld, voldoet dit geval niet. De samenhang van de kosten der overcapaciteit met beide deelen van den afzet is verschillend en de wijze van verbizondering van de kosten zal dan ook een andere moeten zijn.

De structuur van den afzet zal blijken beslissend te zijn voor de verbizondering van de kosten. Wij zullen moeten trachten voor de verschillende casusposities het oorzakelijke verband tusschen overcapaciteit en afzet vast te stellen, teneinde het verband tusschen de kosten van de overcapaciteit en het afgezette goederenkwantum te leeren kennen. Om de behandeling van de gevallen, die zich daarbij voordoen, te vergemakkelijken en te verduidelijken willen wij ons voor de analyse van ons probleem bedienen van een eenvoudig voorbeeld. Dit voorbeeld is niet anders dan een demonstratievoorbeeld, dat ons in staat stelt op gemakkelijke wijze aan de hand van eenige eenvoudig gekozen getallen de verschillende casusposities uiteen te zetten.

Denken wij ons een bedrijf met een seizoenafzet, dat over een productiecapaciteit beschikt, waarmede bij volle bezetting 10.000 producteen heden per maand kunnen worden voortgebracht. De kosten van het ondeelbare productie apparaat bedragen $f$ 120.000. - per jaar. Doordat

4) Een verbizondering van de kosten over de productsoorten wordt alsdan noodzakelijk, omdat het aandeel in de capaciteitskosten per productsoort niet gelijk behoeft te zijn.

5) Bijv. een ijsfabriek met vaste afnemers en een grooteren afzet in de zomermaanden. 
voorraadvorming niet mogelijk is, zetten de seizoenfluctuaties in den afzet zich in de productie voort. ${ }^{6}$ ) Gedurende den seizoentijd, die naar wij aannemen vier maanden duurt, wordt om aan de vraag te voldoen de beschikbare gelijktijdelijke capaciteit van het bedrijf ten volle in beslag genomen en worden derhalve 10.000 eenheden per maand geproduceerd. In het overige deel van het jaar - zoo willen wij veronderstellen - is de afzet slechts 5000 eenheden per maand en wordt dan ook dit aantal eenheden per maand voortgebracht.

Teekent men voor dit bedrijf een productiediagram, dan vindt men de volgende figuur:

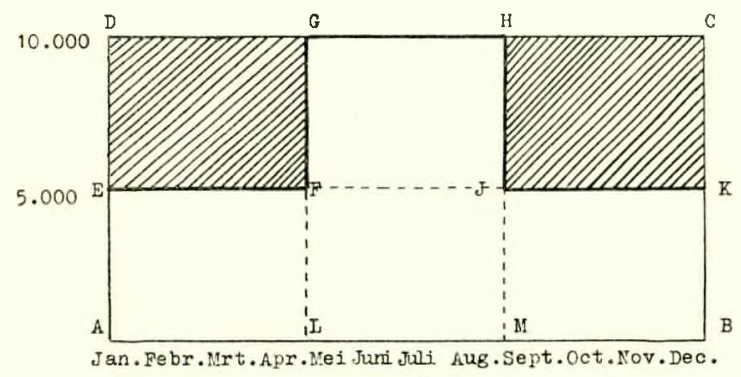

Fig. 1.

In dit diagram wordt de bezetting van de beschikbare productiecapaciteit aangegeven door de getrokken lijn; het gearceerde gedeelte geeft de overcapaciteit aan. De figuur beeldt tevens den omvang van den afzet in de verschillende jaarperioden uit.

Bij onze analyse zal het noodzakelijk zijn de verschillende deelen van den afzet te onderscheiden, waardoor de behoefte zich doet gevoelen aan eenige termen om deze deelen aan te geven. Voor het vervolg van onze beschouwingen zullen wij het deel van den afzet, aangegeven door de letters GFIH aanduiden met den term topafzet, het deel ABKE met basisafzet en het deel GLMH met den term maximumafzet. Aangezien doordat wij voorraadvorming uitsloten - productie en afzet in de perioden van den seizoencyclus gelijken tred houden, kan de hierboven ge maakte onderscheiding ook worden toegepast op de productie. Wij zullen dan ook in het hierna volgende to $p$-, basis- en maximumproductie onder scheiden.

De top in den afzet kan op verschillende wijzen ontstaan. Zij kan worden veroorzaakt door een verhoogde vraag en afzet van de goederen en diensten, die gedurende het geheele jaar worden voortgebracht of bewezen; zij kan ook een gevolg zijn van den afzet van andere artikelen of van de verleening van andere diensten dan die, welke tot den basisafzet behooren. Met betrekking tot de groepen van afnemers, die door hun vraag de seizoendrukte doen ontstaan, treedt als eerste onderscheiding naar voren de indeeling in de afnemers, wier vraag naar de goederen of diensten uitsluitend in de seizoenperiode valt en de afnemers, die geregeld hun goederen betrekken of van de diensten van het bedrijf gebruik maken en daarbij in het seizoen meer afnemen, dan in de overige perioden. Combinaties van deze gevallen zijn uiteraard mogelijk.

$\left.{ }^{6}\right)$ Wij zien voorloopig ook af van andere wijzen, waarop de fluctuaties in de bedrijfsbezetting kunnen worden vervlakt.

$\mathrm{m}$ a b blz, 6 
Wanneer wij de oorzakelijke betrekking tusschen afzet (c.q. productie) en overcapaciteit analyseeren, dan laten zich daarbij drie mogelijkheden denken, t.w.: de kritische oorzaak van het ontstaan van de overcapaciteit moet worden gezocht bij: 1e. den topafzet, 2e. den maximumafzet, 3e bij den basis èn den topafzet. Van deze drie mogelijkheden ligt de eerste het meest voor de hand. Het lijkt zelfs vanzelfsprekend om den topafzet als de kritische oorzaak van het ontstaan van de overcapaciteit aan te wijzen. Voor de topproductie is de grootere productiecapaciteit noodzakelijk en ware de top er niet - zoo zou kunnen worden geredeneerd dan zou een overcapaciteit niet voorkomen. Toch is dit verband niet zoo vanzelfsprekend als dit op het eerste gezicht lijkt. Met evenveel recht kan worden gezegd, dat ware de basisproductie er niet geweest (althans voorzoover het betreft het gedeelte LFIM), geen top en evenmin de overcapaciteit zou zijn ontstaan. Deze laatste redeneering moet logisch leiden tot de conclusie, dat het optreden van de seizoenspits het gevolg is van de cumulatie van top - en basisafzet en dat deze beide tezamen verantwoordelijk zijn voor het ontstaan van de overcapaciteit. Twee beschouwingswijzen staan hier tegenover elkander; welke van deze beide voor een gegeven geval zal gelden, wordt bepaald door de structuur van den afzet. De topafzet kan dan alleen als kritische oorzaak voor het ontstaan van de overcapaciteit worden aangemerkt, indien er geen organische samenhang is tusschen basis en topafzet. Bestaat die samenhang wel (hetgeen meestal het geval zal zijn), dan geldt de tweede beschouwingswijze. In het meerendeel van de gevallen zullen wij den topafzet, doordat deze met den basisafzet samenhangt, niet op zich zelf mogen beschouwen. Niettemin blijft het geval denkbaar, dat de topafzet en daardoor ook de topproductie de overcapaciteit veroorzaakt, n.l. indien de topproductie betrekking heeft op de voortbrenging van andere goederen of het verleenen van andere diensten dan die van de basisproductie. Een dergelijke structuur van afzet en productie komt in de praktijk betrekkelijk zelden voor. Niet uit het oog mag worden verloren, dat als voorwaarde voor deze verbizondering geldt, dat er geen verwantschap in productie of samenhang in afzet bestaat tusschen de voortgebrachte goederen of bewezen diensten in en buiten de seizoenperiode. Voorbeelden van bedrijfshuishoudingen, waarbij deze verbizondering rationeel zou kunnen worden toegepast, zal men moeten zoeken bij bedrijven met een parallelisatie van de productie, welke niet usantieel is voor den bedrijfstak. Men zal zich een bedrijf moeten denken, dat naast zijn hoofdartikel (dat geen seizoenproduct is) een seizoenartikel voortbrengt, dat niet door andere bedrijven uit den zelfden bedrijfstak wordt geproduceerd, zooals bijv. een seizoenspecialité in de mode-industrie.

De verbizondering van de kosten biedt voor dit geval geen moeilijkheden. In wezen moeten hier twee afzonderlijke calculaties worden gemakkt voor twee verschillende producten (of groepen van producten), waarbij de kosten van de overcapaciteit als kosten van de productie, die den top veroorzaakt, moeten worden beschouwd. In ons voorbeeld zou aan het seizoenproduct $f 60.000$. - per jaar voor de capaciteitskosten in rekening moeten worden gebracht, bestaande uit $f$ 20.000. - als kosten van de aangewende werkeenheden in de seizoenperiode en $f$ 40.000.als kosten van de overcapaciteit. Voor het andere product zal $f 60.000-$ moeten worden gecalculeerd. Het voortgebrachte kwantum van beide soorten producten bedraagt $4 \times 5000=20.000$, resp. $12 \times 5000=$ 60.000 eenheden. Het aandeel van de capaciteitskosten in den kostprijs 
van beide producten zal derhalve zijn $f$ 3.- (voor het seizoenartikel), resp. $f$ 1.- per productieeenheid. De relatief hooge kostprijs van het sei zoenartikel tegenover den kostprijs van het andere artikel zal maken, dat de producent eerst dan tot de aanmaak van een dergelijk product zal overgaan, als de te maken prijzen dit loonend maken.

De opvatting, die wij in het voorgaande leerden kennen, n.l. dat de seizoenspits ontstaat door de cumulatie van den topafzet en dat gedeelte van den basisafzet, dat in de seizoenperiode valt, doet de vraag rijzen in welke gevallen de afzet ten tijde van de maximumproductie als de kritische oorzaak van het ontstaan van de overcapaciteit kan worden beschouwd. Een verbizondering van de kosten, waarbij de kosten van de overcapaciteit ten laste van den maximumafzet worden gebracht, vindt men in de praktijk herhaaldelijk toegepast en wel bij die bedrijven met een seizoenvraag, waar de productie buiten het seizoen een incidenteel karakter draagt. De gedachtengang, die aan deze wijze van verbizondering ten grondslag ligt. is de volgende: De productiecapaciteit dient zoo groot te worden gekozen, dat de productie in de vraag op de maximummomenten kan voorzien. 7 ) De omvang van de vraag op het moment, dat deze in de vraag der gezamenlijke afnemers zijn maximum bereikt, is beslissend voor de grootte van de productiecapaciteit, waarover het bedrijf moet beschikken en is daar mede tevens beslissend voor den omvang van de overcapaciteit en de kosten, die daarmede samenhangen. Het zijn derhalve de aanspraken, die door de afnemers op dit maximum van de capaciteit worden gedaan, die de kritische oorzaak vormen van de kosten van de overcapaciteit. Op het maximum moment van de vraag worden 40.000 eenheden afgenomen. Deze maximumafzet vormt in deze gedachte de kritische oorzaak van de totale capaciteitskosten. De totale jaarkosten ad f 120.000. - moeten derhalve worden toegerekend op den afzet in de spits, waardoor het aandeel in de capaciteitskosten van elke producteenheid ten tijde van de maximumproductie $f$ 3. - bedraagt. Aangezien het totaal van de kosten op de maximumproductie wordt verbizonderd, ziin de onbezette werkeenheden buiten de seizoenperiode vrije werkeenheden geworden, aan de aanwending waarvan geen offers zijn verbonden.

De omstandigheid, dat de totale capaciteitskosten (en dus ook de kosten van de overcapaciteit) bij deze wiize van verbizondering ten laste worden gebracht van de productie in het seizoen (maximumproductie), leidt tot een differentieele kostprijsberekening, indien de mogelijkheid zich voordoet om voor de vrije werkeenheden een aanwending te vinden. Een praktische toepassing van deze calculatie vindt men in een hotel, dat alleen gedurende enkele seizoenmaanden is geopend. In de pensionprijzen ge durende deze maanden zullen de totale jaarkosten van de bedrijfsinrichting (dus ook de kosten van de maanden, waarin het bedrijf gesloten is) worden verrekend. Indien bij gunstige weersgesteldheid, wanneer vóór of na het seizoen vraag bestaat naar logies, besloten wordt het hotel vroeger te openen of later te sluiten, behoeft nog slechts met de differentieele kosten rekening te worden gehouden. Buiten het seizoen kan — op volkomen rationeele wiize - de differentieele kostprijsberekening worden toegepast en op grond van den lageren kostprijs zal een dergelijk bedrijf de pensionprijzen in den voor- en natijd lager kunnen stellen dan in het hoogseizoen. Niet mag echter uit het oog worden verloren, dat deze wijze

7) Voorraadvorming sloten wij uit.

m a b blz. 8 
van verbizondering slechts dan juist is, indien er sprake is van een incidenteele verlenging van de seizoenperiode. Zoodra er meerdere seizoenen optreden, zooals zomer- en winterseizoen (b.v. in centra van wintersport) of indien er blijvend buiten de periode van het seizoen vraag naar logies bestaat, moet de organische samenhang van de diensten in deze periodes bij de verbizondering van de kosten in acht genomen worden.

Tal van voorbeelden zijn te noemen van seizoenbedrijven met een incidenteelen afzet buiten de seizoenperiode. Wij bepalen ons tot de bespreking van een enkel typisch geval. Wij kiezen daartoe het wasscherijbedrijf. Langen tijd ondervonden deze bedrijven een seizoenfluctuatie in hun productie als gevolg van de bestaande gewoonte bij het meerendeel der huisvrouwen om des Maandags de wasch te verzenden en deze aan het einde van de week terug te verlangen. Deze seizoenfluctuatie, die haar oorsprong vond in een traditie, leidde ertoe dat de wasscherijen in de laatste dagen van de week geen bezetting hadden voor een deel van hun machines en er een overcapaciteit ontstond. De kosten van deze overcapaciteit kwamen uiteraard ten laste van de in het weekseizoen verwerkte wasch. Paul Atkins, die een onderzoek instelde naar de wijze, waarop in Amerika de bedrijven het seizoenprobleem hebben trachten op te lossen, ${ }^{8}$ ) deelt mede, dat de wasscherijen hebben gezocht naar een aanwendingsmogelijkheid voor de overcapaciteit en daarbij op de gedachte zijn gekomen om lagere tarieven vast te stellen voor de wasch, die in de laatste drie dagen van de week wordt ontvangen voor terugbezorging in het begin van de volgende week. Doordat de kosten van de overcapaciteit reeds in den kostprijs van de diensten zijn gecalculeerd, kunnen de tarieven voor de extrawasch, die het bedrijf nog kan verwerken, op de differentieele kostprijsberekening worden gebaseerd, waardoor deze tarieven lager konden worden gesteld. Door de lagere prijzen ontving de wasscherij ook wasch voor de dagen, waarin zij anders een seizoenslapte had. De differentieele prijspolitiek heeft gunstige gevolgen gehad voor de vergelijkmatiging van de bezetting van het bedrijf. ") De toepassing van deze prijsdiscriminatie heeft verscheidene beperkingen, die wij hier verder buiten beschouwing laten. ${ }^{10}$ ) De beperking, die met betrekking tot ons onderwerp van bizondere beteekenis is, is deze, dat de differentieele kostprijsberekening die aan de lagere tariefvaststelling ten grondslag ligt. slechts tijdelijk zal kunnen worden gevolgd. Zoodra de toevoeging niet meer van tijdelijken aard is, kan de differentieele berekening niet langer worden toegepast. De beide deelen van de productie zullen in organisch verband dienen te worden beschouwd en vanaf dat moment zal de verbizondering van de kosten op integrale wijze moeten geschieden.

Evenals bij de bedrijven met seizoenproductie vindt men bij de bedrijven

8) Paul $M$. Atkins, Solving the Problem of Seasonal Goods, Administration (Ronald Press Company), October 1921.

D) In ons land hebben tal van wasscherijen het seizoenprobleem op bevredigende wijze weten op te lossen, zonder dat zij een differentieele prijspolitiek behoefden toe te passen. Ook ten onzent vindt men echter bij sommige bedrijven verschillende tarieven van de wasch, die in het begin van de week gehaald nog in diezelfde week wordt thuisbezorgd en voor de z.g. "overweeksche" wasch, die eerst in de daarop volgende week wordt afgeleverd. Men vindt zelfs vastrechttarieven, die aan die van het electriciteitsbedrijf doen denken, n.1. een vast bedrag per wasch vermeerderd met een bedrag per kilogram. Dit vast bedrag is voor "overweeksche" wasschen lager dan voor de "weeksche", die de seizoenspits doen ontstaan.

10) De toepassing van prijsdiscriminatie stelt zekere voorwaarden an de wijze van afzet, wil prijsbederf worden voorkomen. Vgl. J. M. Clark, The Economics of Overhead Costs, 1923. chapter XX. Discrimination in the modern market, blz. 416 e.v. 
met een seizoenvraag parallelisatie toegepast als een middel om buiten het seizoen een productieve bestemming aan de overcapaciteit te geven. De Amerikaansche litteratuur geeft aan deze parallelisatie den karakteristieken naam van ,dove-tailing". 11) Tal van typische voorbeelden van ,dovetailing" vindt men opgenomen in de reeds genoemde studie van Atkins. Klassiek welhaast is het voorbeeld van de dagbladdrukkerij, die door de dagspitsen van de productie van ochtend- en avondeditie tot de bedrijven met een dag-,,seizoen" moet worden gerekend. Gedurende een aantal uren per etmaal zijn de zetmachines, drukpersen en de overige technische installatie niet in gebruik. Doordat deze overcapaciteit onvermijdbaar is, behooren - zooals duidelijk zal zijn - de daaraan verbonden offers tot de productiekosten van het courantenbedrijf. De onbezette werkeenheden konden daardoor als ,vrije" werkeenheden worden beschouwd, hetgeen er toe heeft geleid, dat deze drukkerijen de differentieele calculatie hebben toegepast, indien de gelegenheid zich voordeed om een order af te sluiten voor het drukken van een tijdschrift, week - of maandblad, van een boek dan wel voor het uitvoeren van handelsdrukwerken of anderszins, welke ten tijde van den stilstand van de zetmachines en drukpersen konden wor den uitgevoerd. Deze calculatie bood een rationeelen grondslag voor den aanbiedingsprijs van deze toegevoegde productie, zoolang deze parallelisatie een incidenteel karakter droeg. Nu echter de samenvoeging van beide producties een algemeene toepassing in den bedrijfstak heeft verkregen, is de differentieele calculatie niet langer te handhaven. De parallelisatie heeft aan het bedriif het seizoenkarakter ontnomen, doordat de bezetting van de productiecapaciteit is vergelijkmatigd. De beschouwingswijze van de kosten behoort daarbij de integrale te zijn.

(Slot volgt).

\section{HET BESLUIT OP DE DIVIDENDBEPERKING 1941}

door W. Westra

Het Besluit op de Dividendbeperking 1941 (bij het aangeven van artikelen aangeduid met: Besl.), opgenomen in het Verordeningenblad No. 170/1941, en het daarop gegeven aanvullingsbesluit Dividendbeperking 1941, (bij het aangeven van artikelen aangeduid met: Aanv.), opgenomen in de Nederlandsche Staatscourant van 28/29 November 1941, No. 233, treden in werking op 30 Augustus 1941.

Deze besluiten hebben alleen betrekking op vennootschappen, waaronder worden verstaan: binnen het Rijk gevestigde N.V.'s en commanditaire vennootschappen op aandeelen, waarvan het aandeelenkapitaal f 500.000. - of meer bedraagt (art. 7, lid 1, Besl.). Onder aandeelenkapitaal wordt hier verstaan: het nominale bedrag der uitgegeven aandeelen, met inbegrip van de na de uitgifte door de vennootschap ingekochte eigen aandeelen (art. 22, lid 1, Besl). Dit aandeelenkapitaal behoeft dus niet te zijn volgestort.

De uitvoering dezer besluiten is opgedragen aan den inspecteur der directe belastingen of aan den inspecteur der registratie, binnen wiens dienstkring de vennootschap is gevestigd. De volgens deze besluiten verschuldigde belasting moet worden voldaan bij den ontvanger der directe belastingen, onder wiens kantoor de vennootschap is gevestigd.

m a b blz, 10 